\title{
TRATAMENTO ANAERÓBIO DE RESíDUOS ORgÂNICOS COM BAIXA CONCENTRAÇÃO DE SÓLIDOS
}

\author{
ANAEROBIC TREATMENT OF ORGANIC WASTES WITH LOW \\ CONCENTRATION OF SOLIDS
}

\begin{abstract}
VALDERI DUARTE LEITE
Engenheiro Químico - UFPB. Mestre em Engenharia Civil - UFPB. Doutor em Saneamento EESC/USP.

Prof. do DQ/CCT/UEPB

WILTON SILVA LOPES

Químico Industrial - DQ/CCT/UEPB. Mestre em Desenvolvimento e Meio Ambiente - PRODEMA UEPB/UFPB Prof. do DQ/CCT/UEPB

JOSÉ TAVARES DE SOUSA

Engenheiro Químico - UFPB. Mestre em Engenharia Civil - UFPB. Doutor em Saneamento - EESC/USP

SHIVA PRASAD

Bacharel em Química - Jaipur/Índia. Mestre em Química-Jaipur/Índia

Doutor em Química - Jaipur/Î́ndia

Recebido: 03/02/04 Aceito: 22/09/04

RESUMO

O processo de digestão anaeróbia de resíduos sólidos orgânicos com baixa concentração de sólidos é realizado com substrato contendo em média cerca de 5\% (percentagem em peso) de sólidos totais. Os problemas de ordem técnica associados a este tipo de tratamento, estão relacionados ao estudo das configurações de reatores que possam viabilizar uma boa eficiência de transformação do material carbonáceo em um período relativamente curto de tempo. Portanto, neste trabalho foi estudado o processo de digestão anaeróbia de resíduos sólidos orgânicos (RSO) com baixa concentração de sólidos em um reator anaeróbio compartimentado (RAC). O reator anaeróbio compartimentado tinha capacidade unitária de 2200 litros e foi operado com tempo de retenção de sólidos de 90 dias. A eficiência de transformação média de STV foi de $75 \%$ e o biogás produzido continha em média $60 \%$ de gás metano.

ABSTRACT

The process of anaerobic digestion of organic solid wastes with low concentration of solids is accomplished with substratum containing on average about $5 \%$ (percentage in weight) of total solids. The problems of technical order associated to this kind of treatment, are related to the study of the reactors configurations that can make possible a good transformation efficiency of the organic matter in a relatively short period of time. Therefore, in this work it was studied the process of anaerobic digestion of organic solid wastes with low concentration of solids in a compartmented anaerobic reactor (CAR). The compartmented anaerobic reactor had unitary capacity of 2200 liters. The reactor was fed daily with fresh organic solid wastes and with 90 days of solid retention time. The average efficiency of transformation of VTS was of $75 \%$ and the biogas produced contained on average $60 \%$ of methane gas
\end{abstract}

PALAVRAS-CHAVE: reator anaeróbio compartimentado; biogás; resíduos sólidos orgânicos.
KEYWORDS: compartmented anaerobic reactor; biogas; organic solid wastes.

\section{INTRODUÇÃO}

No geral a produção e a composição dos resíduos sólidos é função das atividades humanas e industriais dentro de qualquer contextualização social. Os humanos sempre estiveram e continuam estando associados diretamente aos resíduos por eles produzidos, podendo o resulta- do desta interação ser responsável por diversificadas escalas de agressões ambientais.

Os problemas inerentes à taxa de produção per capita e à composição gravimétrica e físico-química dos resíduos sólidos, principalmente dos resíduos sólidos urbanos, envolvem questôes de natureza social, econômica, política e cul- tural. Em países subdesenvolvidos ou em fase retardada de desenvolvimento, os resíduos sólidos urbanos têm se tornado um problema gravíssimo de saneamento básico e até mesmo de saúde pública.

Segundo IBGE (2001) no Brasil são produzidas em média 125 mil toneladas de resíduos sólidos domiciliares por dia. Deste total cerca de $20 \%$ não são coletados regularmente e dos $80 \%$ 
coletados, que correspondem a $100 \mathrm{mil}$ toneladas, apenas 28 mil toneladas são destinadas de forma racional, sendo a maior fração disposta em aterro sanitário e uma pequena parcela tratada em usina de compostagem. Das 72 mil toneladas de resíduos sólidos domiciliares lançados em lixões, logradouros públicos, canais, margens de rios ou outro qualquer agente receptor, $50 \%$ em média (36 mil toneladas), correspondem a matéria orgânica putrescível. Nos lixões esta matéria orgânica passará pelo processo de bioestabilização aeróbia ou anaeróbia, gerando percolado com elevada concentração de $\mathrm{DQO}$ e ácidos graxos voláteis e, em alguns casos, significativa concentração de metais pesados.

Portanto, se faz necessário o estabelecimento, por parte dos governos municipais, de programas de gerenciamento para os resíduos sólidos urbanos, elegendo a coleta seletiva como ponto prioritário, sendo os materiais papel/papelão, metais ferrosos e não ferrosos, plástico e vidro, encaminhados para usina de reciclagem e a matéria orgânica putrescível destinada para o tratamento por via aeróbia ou anaeróbia, dependendo das prioridades locais.

A digestão anaeróbia é dentre outros, o mais antigo e mais largamente usado processo de tratamento biológico de resíduos (Pavlostathis, 1988) .

A digestão anaeróbia é o mais popular método usado para bioestabilizar lodo primário originado do tratamento de esgoto, convertendo sólidos voláteis para biogás e produtos finais (Neething \& Chung, 1990).

Segundo Baader et al. (1991) todos os resíduos quer sejam de origem animal ou vegetal são bioestabilizados anaerobiamente. No caso de resíduos vegetais, somente os componentes contendo lignocelulose não podem ser bioestabilizados. Segundo Barlaz (1989), tratando-se do processo de bioestabilização da fração orgânica putrescível dos resíduos sólidos urbanos, a celulose e a hemicelulose são responsáveis por aproximadamente $91 \%$ do potencial energético do processo. Ainda segundo Barlaz (1989) foi constatado que a mineralização da celulose e da hemicelulose alcançou valores de $71 \mathrm{e}$ $77 \%$ respectivamente após 111 dias de monitoração do sistema experimental.

O processo de digestão anaeróbia é influenciado por diversos fatores, podendo ser destacados a temperatura, a carga orgânica aplicada, a presença de materiais de natureza tóxica, etc. Em temperaturas altas, as reações biológicas ocorrem com maior velocidade, resultando possivelmente em uma maior eficiência do processo. No geral, o processo anaeróbio poderá ser desenvolvido em temperaturas a nível mesófilo $\left(30\right.$ a $45^{\circ} \mathrm{C}$ ), ou a nível termófilo $\left(45\right.$ a $\left.60^{\circ} \mathrm{C}\right)$. Quanto à carga orgânica, já foram testadas diferentes cargas para diferentes tipos de reatores e substratos. Em comparação com outros tipos de tratamentos, o processo anaeróbio responde satisfatoriamente bem às flutuações de carga, principalmente quando os reatores já se encontram operando em estado de equilíbrio dinâmico.

No tocante à utilização do processo anaeróbio para tratamento de resíduos sólidos, foram intensificados estudos desde a década de 60, objetivando o desenvolvimento de tecnologias para recuperação de energia e a redução da massa de resíduos sólidos orgânicos (Peres et al., 1991). Na década de 70 ocorreu um significativo impulso dos sistemas de tratamento anaeróbio de resíduos, principalmente de resíduos líquidos, haja vista, a realização de trabalhos que passaram a demonstrar um melhor entendimento do processo, principalmente, nos seus aspectos biológicos (Florêncio \& Kato, 1999). Até o presente, ainda não existe a produção de conhecimento tecnológico que possa viabilizar o tratamento anaeróbio de resíduos sólidos orgânicos, no mesmo nível que se tem para resíduos líquidos.

Segundo Vazoller (1999) o sistema mais usual de disposição e/ou tratamento de resíduos sólidos urbanos é o aterro sanitário. Diversas outras configuraçōes de reatores precisam ser investigadas, levando-se em consideração a relação custo/benefício que possa se adequar às realidades regionais e locais. Portanto, objetiva-se neste trabalho desenvolver alternativas tecnológicas de aproveitamento integral dos resíduos sólidos orgânicos, propor cionando a redução dos impactos ambientais causados atualmente pelo lançamento inadequado destes resíduos.

\section{MATERIAL E MÉTODOS}

O trabalho experimental foi realizado nas dependências da Estação Experimental de Tratamentos Biológicos de Esgotos Sanitários (EXTRABES), localizada no Bairro do Tambor na cidade de Campina Grande estado da Paraíba no Nordeste do Brasil. O sistema experimental era constituído por dispositivo para preparação dos resíduos sólidos orgâni- cos, de uma caixa de alimentação e de um reator anaeróbio compartimentado com capacidade unitária de 2200 litros. O reator anaeróbio compartimentado foi construído de fibra de vidro e assentado em uma base metálica. O reator possuía configuração geométrica retangular e foi dividido internamente em três câmaras de iguais dimensôes. Em cada câmara foi instalado um ponto de coleta de amostras, objetivando realizar o acompanhamento do perfil de distribuição do material sólido ao longo do sentido longitudinal do reator. Do volume total do reator, uma fração em torno de 300 litros foi destinada para armazenamento do biogás produzido. Na Figura 1 apresenta-se o esquema geral do reator anaeróbio compartimentado.

A capacidade volumétrica total do reator era de $2,2 \mathrm{~m}^{3}$, sendo que deste volume, $1,85 \mathrm{~m}^{3}$ eram destinados ao substrato e o restante ao acúmulo de biogás. O reator foi operado com tempo de detenção de sólidos de 90 dias o que forneceu ao reator uma carga orgânica aplicada de $9,3 \mathrm{kgRSO} \cdot \mathrm{m}^{-3} \cdot \mathrm{dia}^{-1}$. O reator foi monitorado durante um período de 140 dias. A estabilidade do processo era avaliada tomando-se como referencial o material afluente, efluente e acumulado no sistema operacional.

Os resíduos sólidos orgânicos utilizados para alimentação do reator eram constituídos de resíduos sólidos vegetais e de lodo de esgoto sanitário na proporção de 80 e $20 \%$, respectivamente. A mistura destes dois tipos de resíduos originava o substrato, o qual após a correção da umidade para $95 \%$ (percentagem em peso) alimentava o reator.

A monitoração do sistema experimental consistiu na coleta dos resíduos sólidos orgânicos, na preparação do substrato e alimentação do reator diariamente, além do acompanhamento sistemático do perfil de distribuição de resíduos nas câmaras internas do reator.

A monitoração foi realizada nas frações sólidas, líquidas e gasosas. $\mathrm{Na}$ fração sólida, as análises foram realizadas nos resíduos sólidos vegetais, no lodo de esgoto sanitário e no substrato, sempre antes da alimentação do reator. $\mathrm{Na}$ fração líquida as amostras eram coletadas semanalmente e determinados os seguintes parâmetros: $\mathrm{pH}, \mathrm{ST}$ e suas frações, alcalinidade total, ácidos graxos voláteis, DQO, NTK e nitrogênio amoniacal. Para realização das análises físicas e químicas da fração líquida utilizaram-se os métodos preconizados por APHA et al. (1995). Na fração 
gasosa, a quantificação do biogás era realizada continuamente, sendo a caracterização qualitativa feita duas vezes por semana através de cromatografia gasosa.

\section{RESULTADOS E DISCUSSÃO}

O processo de bioestabilização anaeróbia de resíduos sólidos orgânicos gera percolado com elevada demanda química de oxigênio e biogás que, dependendo da estabilidade do processo pode conter de 10 a $60 \%$ de gás metano, além de material orgânico parcialmente bioestabilizado contendo micro e macronutrientes essenciais para serem incorporados em solos agrícolas.

Um dos parâmetros que está sendo estudado com bastante empenho no processo de bioestabilização anaeróbia de resíduos sólidos orgânicos é o percentual de umidade. $\mathrm{O}$ ajuste do percentual ótimo de umidade para o desempenho do processo contribuirá tecnicamente para se alcançar um maior índice de transformação de matéria orgânica e reduzirá os custos de implantação do sistema experimental, equilibrando favoravelmente a relação custo/benefício do tratamento, razão pela qual se realizou este trabalho com substrato contendo 5\% de sólidos totais. Os resíduos sólidos domiciliares, no geral apresentam características predominantemente orgânicas, haja vista, serem formados por restos de alimentos, frutas e verduras.

Na Figura 2 apresenta-se o comportamento do $\mathrm{pH}$ do material afluente e efluente do reator durante os 140 dias relativos ao período de monitoração.

Analisando os dados do $\mathrm{pH}$, constata-se que os resíduos sólidos apresentavam características ligeiramente ácidas, com valores de $\mathrm{pH}$ variando de 3,4 a 5,6. Mesmo trabalhando-se com substrato apresentando $\mathrm{pH}$ médio em torno de 5,0, não foi adotada nenhuma medida para correção do $\mathrm{pH}$, mesmo sabendo-se que o $\mathrm{pH}$ ideal recomendado para o processo de tratamento anaeróbio é de 6,5 a 7,5 Nos primeiros 100 dias de monitoração, o $\mathrm{pH}$ do material efluente do reator, também apresentava características ácidas, haja vista, os valores de $\mathrm{pH}$ estarem em torno de 5,0. Após os 100 dias de monitoração os valores de $\mathrm{pH}$ do material efluente cresceram gradativamente, chegando a atingir valores de 8,0 aos 140 dias de monitoração.

A quantificação dos valores de $\mathrm{pH}$ em processos de tratamento biológico de

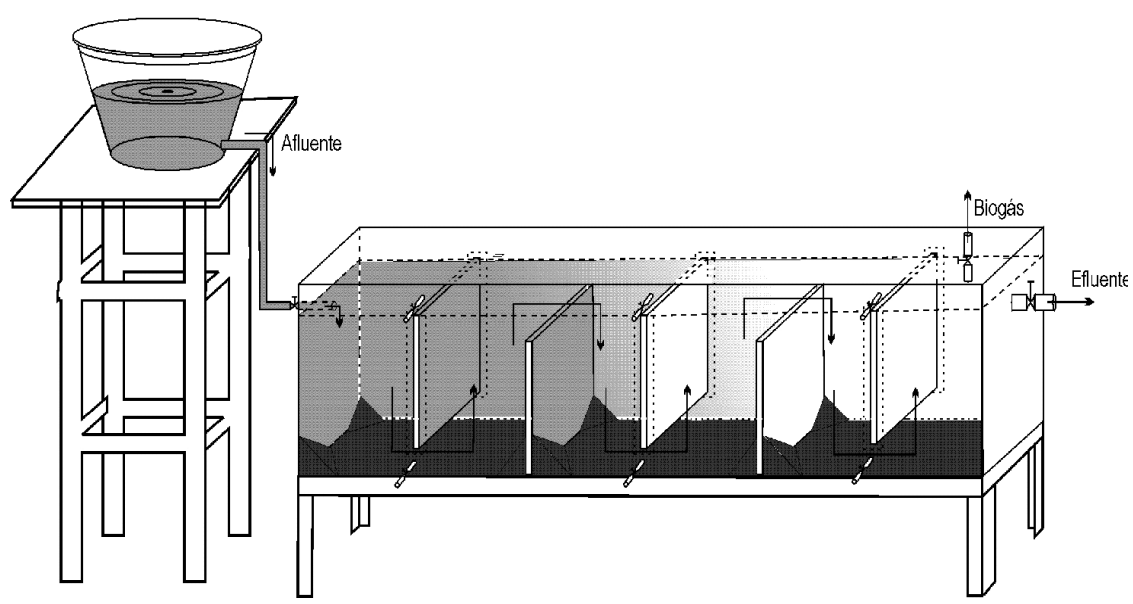

Figura I - Esquema geral do reator anaeróbio compartimentado

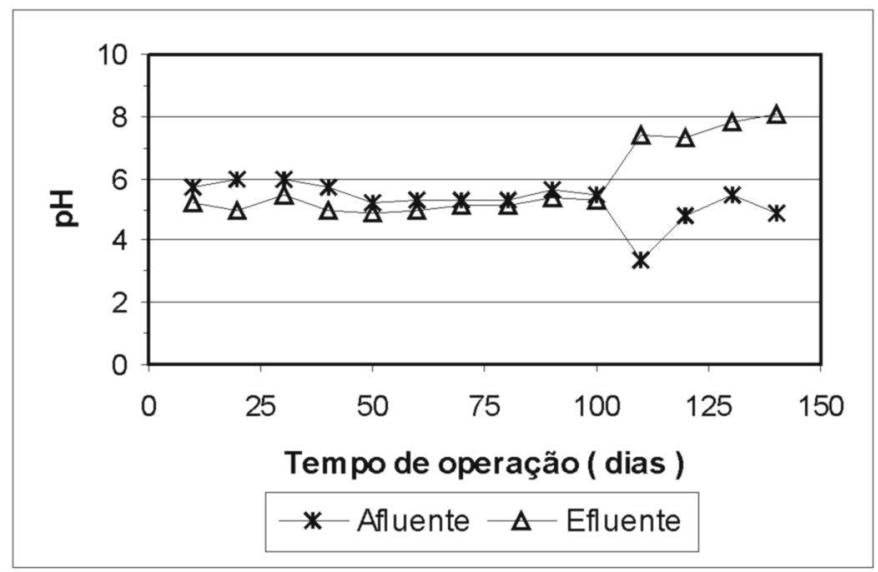

Figura 2 - Comportamento do pH do material afluente e efluente do reator

resíduos sólidos ou líquidos avalia preliminarmente o desempenho do processo. $\mathrm{Na}$ Figura 3 são mostradas as tendências da alcalinidade total do material afluente e efluente.

A alcalinidade total representa a soma da alcalinidade advinda dos ácidos graxos voláteis e dos bicarbonatos. Para resíduos com pH em torno de 5,0, a alcalinidade total é constituída basicamente por sais derivados de ácidos graxos voláteis. Neste trabalho a alcalinidade total do substrato variou de 1,8 a $5,0 \mathrm{gCaCO}_{3} \cdot \mathrm{L}^{-1}$. No material efluente a alcalinidade total variou de 3,8 a $4,8 \mathrm{gCaCO}_{3} \cdot \mathrm{L}^{-1}$, não tendo sido constatado um acréscimo constante da alcalinidade total em função do tempo de operação. Somente após os 120 dias de monitoramento da alcalinidade presente nos líquidos efluentes a maior fração correspondia a alcalinidade de bicarbonato. No período anterior aos 120 dias, constatou-se que a alcalinidade total era constituída em sua maior parte por sais de ácidos graxos voláteis. A relação ácidos graxos voláteis/alcalinidade total, que no início do processo se situou em torno de 2,5 foi decrescendo bruscamente até alcançar valores em torno de 0,05. Para processos de tratamento anaeróbio, a relação ácidos graxos voláteis/alcalinidade total em torno de 0,5 favorece o estado de equilíbrio dinâmico no reator e o biogás produzido passa a conter em média $60 \%$ (percentagem em volume) de gás metano.

O comportamento da evolução temporal da concentração de ácidos graxos voláteis é mostrado na Figura 4.

Nos processos de tratamentos biológicos a eficiência de transformação de material orgânico está associada à presença de uma equilibrada massa bacteriana, que seja capaz de suportar as variaçōes de cargas orgânicas aplicadas, à presença de materiais com características tóxicas no 
substrato e às variaçôes das condições ambientais.

Neste trabalho foi constatada uma boa eficiência de transformação de material carbonáceo, principalmente sólidos totais voláteis. O comportamento da evolução temporal dos sólidos totais voláteis é mostrado na Figura 5.

A concentração de sólidos totais voláteis no material afluente variou de 18,10 a $31,75 \mathrm{~g} . \mathrm{L}^{-1}$ no período de operação do sistema experimental. No material efluente a concentração de sólidos totais voláteis variou entre 2,2 e 6,60 g. $\mathrm{L}^{-1}$, proporcionando uma redução média de 80\%. A eficiência de redução de STV estimada neste trabalho está associada à fração retida no interior do reator e à fração convertida em biogás. Estima-se que da fração de STV retida no interior do reator, em média, $75 \%$ do material predominantemente orgânico e mais solúvel estejam sendo bioestabilizados, convertendo-se em biogás durante o período de retenção de sólidos que foi de 90 dias. $\mathrm{O}$ material orgânico mais particulado permanecerá no interior do reator, podendo ser bioestabilizado posteriormente, atingindo a fase de completa mineralização. A eficiência de redução e, conseqüentemente, de transformação de massa de STV tem sido função das propriedades físicas e químicas do substrato, da carga orgânica aplicada e do tempo de retenção de sólidos.

Em escala real a relação custo/beneficio deste tipo de tratamento é função direta da eficiência de transformação de sólidos totais voláteis, haja vista, a otimização do sistema no sentido de se trabalhar sempre com elevada carga orgânica.

$\mathrm{Na}$ Figura 6 são apresentadas as variaçóes da DQO do material afluente e do efluente do reator ao longo do período de monitoração.

A concentração de DQO do material afluente variou de 8,94 a 32,74 g.L $\mathrm{L}^{-1}$, enquanto no material efluente variou de 1,06 a $10,55 \mathrm{~g} \cdot \mathrm{L}^{-1}$, com uma eficiência de redução de massa de $\mathrm{DQO}$ variando de 50 a $94 \%$. A significativa variação da redução de massa de DQO se deve prioritariamente às flutuações da concentração de DQO no material afluente, que, por sua vez, estão associadas à heterogeneidade dos resíduos sólidos orgânicos. Em se tratando de resíduos desta natureza, as variaçôes bruscas da concentração de $\mathrm{DQO}$, poderão ser atenuadas com a segregação dos diferentes tipos de resíduos, realizando-se em seguida uma representativa homogeneização e tritura-

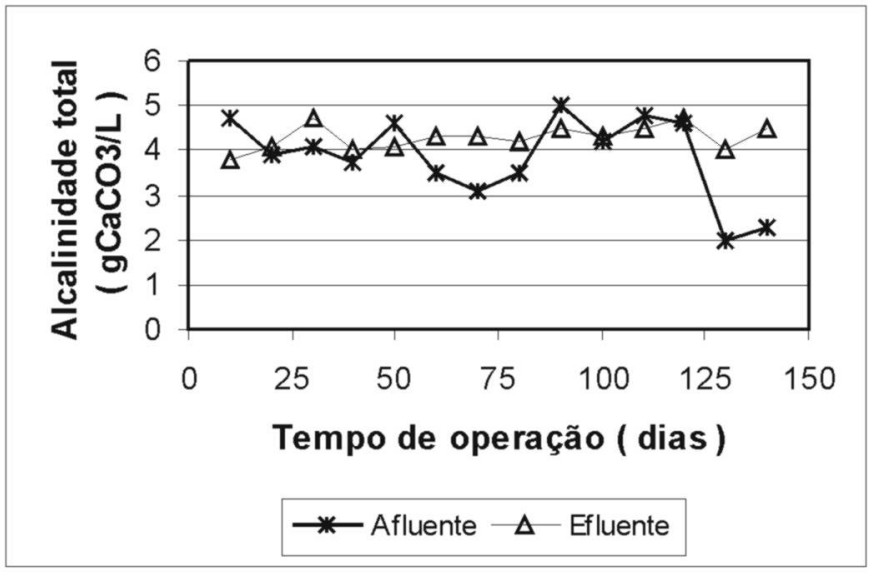

Figura 3 - Perfis da alcalinidade total do material afluente e efluente

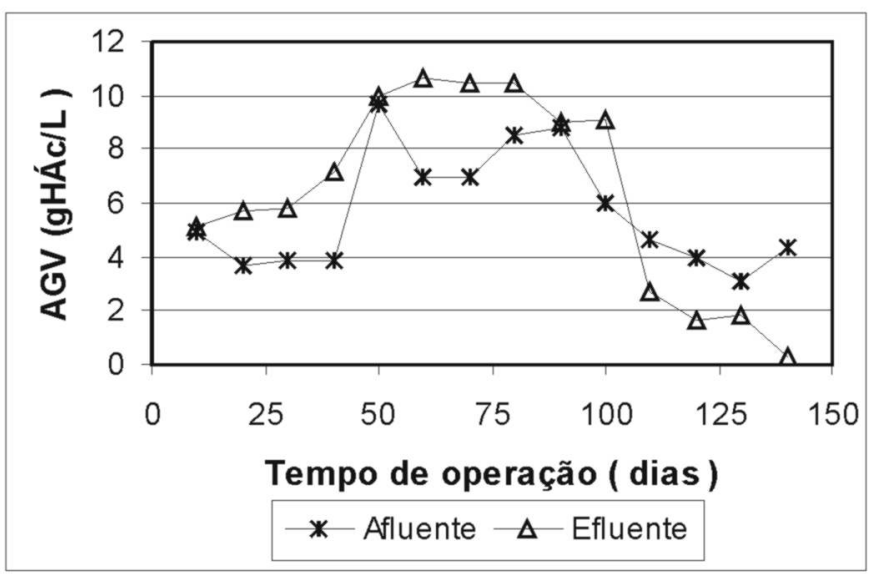

Figura 4 - Comportamento da evolução temporal da concentração de ácidos graxos voláteis

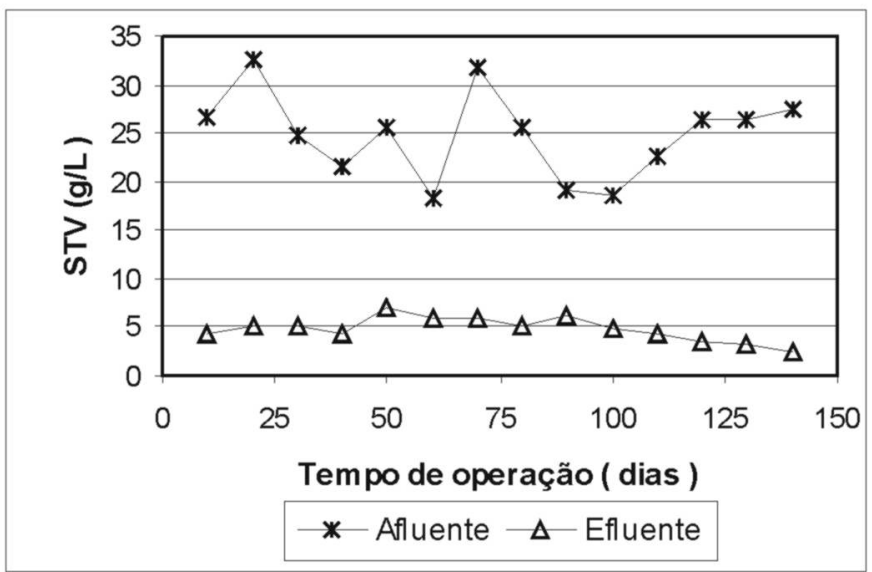

Figura 5 - Comportamento da evolução temporal dos sólidos totais voláteis 


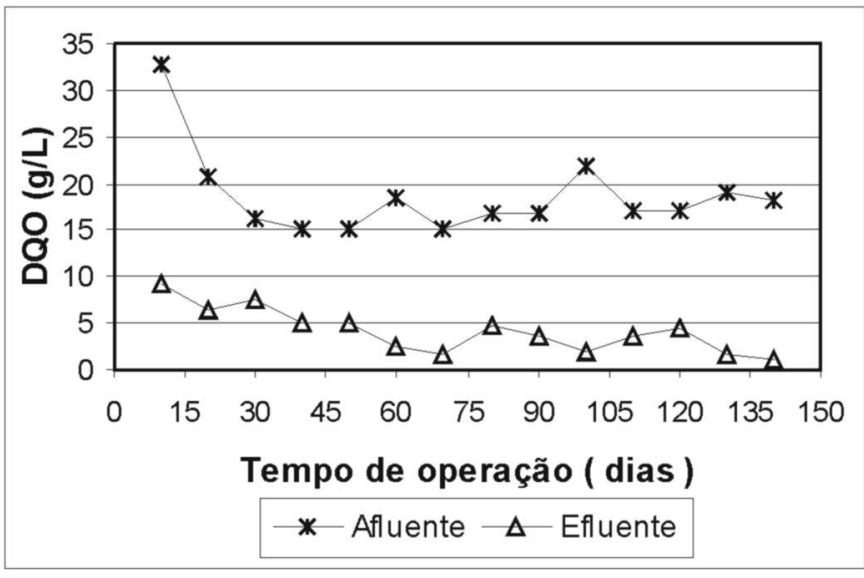

Figura 6 - Perfil da DQO nos líquidos afluentes e efluentes do reator

ção. A homogeneização dos diferentes tipos de resíduos possibilita além da regularização quantitativa da concentração de DQO, a correção da acidez ou da basicidade natural do substrato, além de melhorar substancialmente a sua composição nutricional. É recomendável se trabalhar sempre com uma equilibrada relação $\mathrm{C} / \mathrm{N}$ e demais outros tipos de macro e micro nutrientes. Projetar um reator que possibilite eficiência de transformação de material carbonáceo em torno de $80 \%$, tornará o sistema altamente competitivo com as demais outras formas de tratamento de resíduos sólidos orgânicos e contribuirá substancialmente para a preservação dos recursos naturais e a redução da poluição do solo, da água e do ar.

Com relação à produção volumétrica de biogás, pode ser verificado que esta aumentou gradualmente em função do equilíbrio estabelecido entre os diferentes grupos de microrganismos responsáveis pelo processo de bioestabilização do material orgânico. A produção diária de biogás foi bastante significativa, tendo o volume produzido variado entre 40 e 200 litros, propiciando uma média de 120L.dia ${ }^{-1}$ de biogás durante o período. Tomando-se como referencial este dado, obtém-se uma taxa de produção de biogás de 5,6 L. $\mathrm{kg}^{-1}$ de substrato aplicado (em base úmida).

Na composição do biogás foi identificado significativo percentual volumétrico de gás metano, principalmente quando o reator alcançou o estado de equilibro dinâmico. Nos dias iniciais da operação, o biogás produzido era constituído basicamente por $\mathrm{CO}_{2}$ e $\mathrm{N}_{2}$. Com o passar do tempo e em consonância com a elevação do $\mathrm{pH}$ e a redução da concentração de ácidos graxos voláteis nos líquidos percolados, teve início a produção do gás metano, com percentual sempre crescente na composição geral do biogás, chegando a atingir o patamar de $68 \%$ (percentagem em volume), após os primeiros quatro meses de operação. O valor médio do teor de metano durante o período de operação do reator situou-se em torno de $60 \%$ (percentagem em volume).

\section{CONCLUSÃO}

Frente à análise dos dados deste trabalho, pode-se concluir que:

- o processo de tratamento anaeróbio de resíduos sólidos orgânicos com baixa concentração de sólidos desponta como uma alternativa tecnológica para o tratamento integral dos resíduos sólidos orgânicos, fornecendo como produtos o biogás e composto bioestabilizado;

- trabalhando-se com carga orgânica aplicada de $9,3 \mathrm{kgRSO} \cdot \mathrm{m}^{-3} \cdot \mathrm{dia}^{-1}$ a eficiência de redução de material carbonáceo situou-se em torno de $80 \%$;

- o biogás produzido pode ser considerado como uma boa fonte energética, haja vista, conter em média $60 \%$ de gás metano;

- a eficiência de transformação de material carbonáceo é função das características físicas e químicas do substrato, da carga orgânica aplicada e do tempo de retenção de sólidos no interior do reator.

\section{AGRADECIMENTOS}

Os autores deste trabalho agradecem o apoio financeiro concedido pela FINEP/PROSAB e Banco do Nordeste do Brasil (BNB) para a realização deste trabalho e ao CNPq pela concessão das bolsas de pesquisa.

\section{REFERÊNCIAS}

APHA, AWWA, WPCF. Standard Methods for the Examination of Water and Wastewater. $18^{\text {th }}$ ed. Washington, 1134p. 1995.

BAADER, W. et al. Biotechnological methods for the utilization of residues and byproducts of agriculture. Institute for Technology. V. 3, 265p. 1991.

BARLAZ, M. et al. Mass balance analyses of anaerobically decomposed refuse. Journal of Environmental Engineering. V. 119, n. 1, p.39-56, 1993

FLORENCIO, M de L.; KATO, M. T. Sistema de tratamento anaeróbio. Apostila do IV Curso de tratamento biológico de resíduos, FURB/UFSC, Florianópolis, p.24. 1999.

IBGE. Anuário Estatístico do Brasil, Brasília, 2001.

NEETHING, J.; CHUNG, Y. C. Microbial activity measurements for anaerobic sludge digestion. Journal WPCF. V. 61, 4-3, 1989.

PAVLOSTHATHIS, S. G. Preliminary conversion mechanisms in digestion anaerobic of biological sludge. Journal of Environmental Engineering. V. 114, n. 4, p. 10-12, 1988.

PERES, C. S. et al. Anaerobic biodegradability of the organic components of municipal solid waste. São Paulo, Brasil. Paper preprints. VI International Symposium of Anaerobic Digestion, p. 12-16, 1991.

VAZOLLER, R. F. Microbiologia e saneamento ambiental. Disponível em: http://www.bat.org.br/ martinez/padct.bio/cap.9/rosana, acesso em: 02 agosto 1999

Endereço para correspondência:

Valderi Duarte

Rua Vigário Calixto, 1475 - Catolé 58 1 06-485 Campina Grande - PB Brasil

Tel.: (83) 337-33 I6

E-mail: valderileite@uol.com.br 